\title{
Stereotactic body radiation therapy (SBRT) for early stage non- small cell lung cancer (NSCLC): contemporary insights and advances
}

\author{
Nikhil T. Sebastian, Meng Xu-Welliver, Terence M. Williams \\ Department of Radiation Oncology, The Ohio State University Comprehensive Cancer Center, Arthur G. James Cancer Hospital and Richard J. \\ Solove Research Institute, OH, USA \\ Contributions: (I) Conception and design: NT Sebastian, TM Williams; (II) Administrative support: None; (III) Provision of study materials or \\ patients: None; (IV) Collection and assembly of data: NT Sebastian, TM Williams; (V) Data analysis and interpretation: NT Sebastian; (VI) \\ Manuscript writing: All authors; (VII) Final approval of manuscript: All authors. \\ Correspondence to: Terence M. Williams, MD, PhD. Department of Radiation Oncology, The Ohio State University, 460 West $10^{\text {th }}$ Avenue, \\ Columbus, OH 43210, USA. Email: Terence.Williams@osumc.edu.
}

\begin{abstract}
The standard-of-care treatment for early-stage non-small cell lung cancer (NSCLC) continues to be surgery in the form of lobectomy or pneumonectomy. Stereotactic body radiation therapy (SBRT) has evolved as a viable alternative to surgery for medically inoperable patients, achieving excellent local control (LC) with relatively minimal toxicity in standard-risk patients. Nevertheless, the maturation of SBRT has fostered debate regarding its use, technique, dose, and fractionation, particularly in the context of patientand disease-specific characteristics such as tumor size and location. This review will cover the recent trends and future directions of SBRT as it becomes an increasingly individualized modality in the treatment of early-stage NSCLC.
\end{abstract}

Keywords: Non-small cell lung cancer (NSCLC); early-stage lung cancer; stereotactic ablative radiotherapy (SABR)

Submitted Oct 14, 2017. Accepted for publication Apr 09, 2018.

doi: $10.21037 /$ jtd.2018.04.52

View this article at: http://dx.doi.org/10.21037/jtd.2018.04.52

\section{Introduction}

Despite the decline of smoking in the past several years (1), lung cancer remains the second most common cancer in men and women, but remains the most common cause of cancerrelated death, accounting for over one-quarter of cancerrelated deaths in the United States. There are over 200,000 new cases of lung cancer each year (2), approximately $85 \%$ of which are non-small cell lung cancers (NSCLCs), the predominant histologic type. Roughly $15 \%$ of NSCLCs are at an early, localized stage at presentation (3). Surgery, in the form of lobectomy, bi-lobectomy, or pneumonectomy, remains the standard of care in early stage (T1T2N0) NSCLC and results in 5-year survival rates of $60-70 \%$ (4-6). These anatomic pulmonary resections are preferred over sublobar resections due to previous data suggesting inferior survival outcomes with lesser surgery (7), but sublobar resection (including wedge and segmentectomy) can be considered appropriate for patients at high-risk for lobectomy and who have a small peripheral nodule (ideally $2 \mathrm{~cm}$ or less).

Patients deemed medically inoperable, either due to comorbidity or refusal of surgery, have historically been treated with definitive conventionally-fractionated external beam radiotherapy over 6-7 weeks with generally inferior results to surgery (reported 5-year survival range from $6-32 \%$ ). This is likely in part due to selection bias (since medically inoperable patients typically have more medical co-morbidities and are older), and the inferiority of clinical $v s$. pathologic staging (8-11). Given these inadequate outcomes, there have been multiple attempts at dose- 
escalation, many of which demonstrate benefit $(9,12-16)$ and few that do not $(17,18)$.

Since its development in the 1990s at the Karolinska Institute in Stockholm, Sweden as an adaptation of intracranial stereotactic radiosurgery (19), SBRT [synonym stereotactic ablative radiotherapy (SABR)] has emerged as one of the most significant advances in modern radiotherapy. By utilizing accurate target delineation, motion management, conformal treatment planning, and daily image guidance, SBRT is able to deliver high doses in few fractions and provide a steep dose fall-off outside the target $(20,21)$. As a natural extension of attempts at dose-escalation in the setting of lung cancer, SBRT has now become the standard of care in early stage medically inoperable NSCLC, with excellent local control (LC) rates (22-24). Despite this, the growing body of data available suggests continued progress will come from maximizing efficacy while minimizing toxicity, as well as tailoring treatment for high-risk clinical scenarios (24).

\section{Dose optimization and outcomes for peripheral vs, central tumors}

\section{Peripheral tumors}

The pioneering prospective dose-finding SBRT study was conducted at Indiana University and determined maximal tolerable doses in 47 medically inoperable patients to be $3 \times 20$ Gy and $3 \times 22$ Gy for T1 and T2 lesions, respectively. Crude LC rate was $79 \%$, however only 1 of the 10 local failures occurred in patients receiving $>16$ Gy per fraction (25). In another prospective study, 57 patients in Nordic countries were treated with 45 Gy in 3 fractions to the $67 \%$ isodose line, achieving 3 -year LC and overall survival (OS) of $92 \%$ and $60 \%$ respectively (26). Subsequently, in a landmark phase II multicenter study by Timmerman et al. (27), 70 patients with T1-2N0 inoperable tumors were treated with 60 and 66 Gy in 3 fractions, respectively, for T1 and T2 tumors. Despite excellent 2-year LC of $95 \%$, toxicity was unacceptably high. Toxicity from SBRT correlated with tumor location, with freedom from grade $3+$ toxicity $83 \% v s$. $54 \%$ between peripheral vs. central lung tumors (27).

The aforementioned phase I and II studies were the foundation for Radiation Therapy Oncology Group (RTOG) 0236 (May 2004-Oct 2006), a phase II multicenter trial that treated patients with $60 \mathrm{~Gy}$ in 3 fractions, but excluded patients with tumors in the defined "central zone" of the lung within $2 \mathrm{~cm}$ of the proximal bronchial tree. The prescription dose of 60 Gy in 3 fractions was assuming all water density; with tissue inhomogeneity corrections, the effective dose was determined to be 54 Gy in 3 fractions (28). With 55 evaluable patients and a median follow up of 4 years, 5 -year local failure, locoregional, and disseminated failure were $20 \%, 38 \%$, and $31 \%$, respectively. Diseasefree and OS were $26 \%$ and $40 \%$, respectively. Importantly, toxicity was acceptable, with 15 patients experiencing grade 3 toxicity and 2 patients experiencing grade 4 toxicity (29).

\section{Central tumors}

The notion that central tumors have a higher propensity for severe toxicity compared with peripheral tumors spurred a number of studies evaluating the appropriate dose and fractionation for higher-risk central tumors (Table 1). RTOG 0813 (Feb 2009-Sep 2013), a seamless phase I/II study, sought to evaluate the toxicity of centrally located tumors using escalated doses beginning with 50 Gy in 5 fractions escalated by 0.5 Gy per fraction to a maximum dose of $60 \mathrm{~Gy}$ in 5 fractions. The most recent data with median of 30-33 months shows 2-year LC of 89.4\% (57.5 Gy cohort) and $87.7 \%$ (60 Gy cohort) and grade 3+ toxicity in $6 / 38$ patients $(16 \%)$ in the 57.5 Gy cohort and $7 / 33$ patients $(21 \%)$ in the 60 Gy cohort. A total of 3 grade 5 toxicities attributed to SBRT were reported, 2 in the 57.5 Gy cohort, 1 in the 60 Gy cohort. Two-year OS of $70-72 \%$ was comparable to patients treated with peripheral tumors. Of note, "central tumors" in this study were considered those within $2 \mathrm{~cm}$ of the proximal bronchial tree and immediately adjacent to mediastinal or pericardial pleura, to account for the complexity of treating tumors close to critical mediastinal organs at risk (30).

The Nordic HILUS trial (2011-2016) was a phase II nonrandomized multicenter trial of SBRT to central tumors, defined as $\leq 1 \mathrm{~cm}$ from the proximal bronchial tree, and included both primary NSCLC and progressive metastases from other primary sites. All patients received 7 Gy $\times 8$ fractions. Of the 74 patients, 42 had tumors close to the main bronchus ( $\operatorname{arm~A}$ ) and 31 had tumors close to a lobar bronchus (arm B). Twenty-eight percent of patients experienced grade $3+$ toxicity and 7 patients (6 of these in arm A) experienced grade 5 side effects (lethal hemoptysis in 6 patients and pneumonitis in 1 patient). Grade 4+ side effects were more common in arm A vs. B (19\% vs. 3\%). Given the overall high rate of serious toxicity, particularly with tumors in close proximity to the main bronchus, the authors expressed the need for further study of clinical and 
Table 1 Studies of SBRT to central/ultracentral tumors



*, defined as $\leq 2 \mathrm{~cm}$ from PBT, major vessels, esophagus, heart, trachea, pericardium, brachial plexus, or vertebral body, but $1 \mathrm{~cm}$ from spinal canal; ${ }^{\dagger}$, rate of Grade 2-3 dermatitis and chest wall pain; ${ }^{\ddagger}$, per institutional dose constraints. y, years; mo, months; n, number of patients evaluated; SBRT, stereotactic body radiation therapy; LC, local control; OS, overall survival; G3+T, Grade 3+ toxicity; G5, Grade 5 toxicity; PBT, proximal bronchial tree; fx, fractions.

dose-volume risk factors (31).

In a separate Dutch study, 63 patients with central tumors treated with 60 Gy in 8 fractions had 3-year LC of $92.6 \%$, while 4 patients (6\%) had late grade III toxicity, but no grade IV/V toxicity (32). In a separate study of 27 Stage I patients $(\mathrm{n}=13)$ and patients with isolated recurrences $(\mathrm{n}=14)$ at MD Anderson, $50 \mathrm{~Gy}$ in 4 fractions was delivered to superiorly and centrally located tumors, defined as $2 \mathrm{~cm}$ in all directions of any mediastinal critical structure. With a median follow-up of 17 months, crude LC was $100 \%$ and there were no occurrences of esophagitis or grade 2 pneumonitis (33).

An influential report of late grade 5 central airway necrosis in a patient treated with 50 Gy in 5 fractions to a central tumor (40) prompted studies further stratifying central tumors into those that are "ultracentral", with gross or planning target volumes abutting or overlapping the trachea, primary bronchial tree, or esophagus. The first study to retrospectively evaluate this specific cohort determined good outcomes and few toxicities comparable to central and peripheral tumors (35). In an MD Anderson study, 70 Gy in 10 fractions was found to achieve excellent LC (2-year LC 96.2\%) with acceptable toxicity for challenging cases not amenable to a 4-fraction regimen, particularly due to concerns of chest wall and brachial plexus toxicity with a four fraction technique (36). In a Dutch retrospective study of 47 patients with ultracentral tumors overlapping the trachea or main bronchus, $60 \mathrm{~Gy}$ in 12 fractions was found to be efficacious with regard to local tumor control (LC 100\%, median follow-up 29 months), but grade $3+$ toxicity was noted in $38 \%$ of patients, with $21 \%$ of patients having possible or likely treatment related death. Fatal pulmonary hemorrhage was observed in $15 \%$ of patients. While the authors noted that the fatal toxicity rates of conventionally fractionated radiation for endobronchial tumors are similar, the authors concluded that the $15 \%$ grade 5 toxicity rate is concerning and merits further evaluation (37). Indeed, a recent multi-institutional 
retrospective study demonstrated a $>3.5$-fold increased risk of non-cancer related death in patients with a tumor $<1 \mathrm{~cm}$ from the proximal bronchial tree (38) and multiple other single-institution experiences echo these concerns $(39,40)$. Thus, while reported institutional experiences have shown reasonably good outcomes in this high-risk cohort, particularly with more protracted regimens, the concern for unacceptable rates of fatal toxicity remains and necessitates further study with long term follow up.

\section{Dose intensity and volume-adapted dosing}

A number of dose-response studies have demonstrated the importance of dose-intensity for tumor control (41-45). Biologic effective dose (BED) is an equivalent dose used to compare different dose and fractionation regimens, and is most often calculated using the linear quadratic formula. A relatively large retrospective Japanese study that included $\mathrm{T} 1$ and $\mathrm{T} 2$ tumors in any location showed improved 5-year LC and survival with $\mathrm{BED}_{\text {iso }} \geq 100 \mathrm{~Gy}_{10}$ (91.6\% vs. $57.1 \%$ and $53.9 \%$ vs. $19.7 \%$ respectively) (32). Given the variety of dosing schemes available, comparisons utilizing BED are convenient and this finding offer a valuable benchmark for evaluating treatment efficacy, notwithstanding the decreased accuracy of the linear quadratic model at high dose per fraction (46).

Recently, volume has been integrated into dose-response studies and found to be a modifier of treatment response. One study identified 11 -month LC of up to $100 \%$ for tumors with gross tumor volume (GTV) $\leq 12 \mathrm{~mL}$ but $47 \%$ for tumors with GTV $>12 \mathrm{~mL}$ (47). On this premise, Trakul et al. conducted a retrospective analysis of 83 patients treated with a volume-adapted dosing strategy in which tumors $<12 \mathrm{~mL}$ received single-fractions with $\mathrm{BED}<100 \mathrm{~Gy}$ and tumors $>12 \mathrm{~mL}$ received multifraction regimens with BED $\geq 100$ Gy. LC at 12 months for these groups was $92.6 \%$ and $91.7 \%$ and grade $3+$ toxicity was $0 \%$ and $11.4 \%$, respectively. There was no difference in regional control, distant metastasis, or OS (48). Thus, it appears that dose reduction for smaller tumors may be efficacious and may spare patients from unnecessary toxicity, although longer follow-up and additional studies are needed.

\section{Single-fraction SBRT}

Although SBRT is commonly delivered in multiple fractions, single-fraction SBRT has been evaluated in multiple single-institution studies using doses ranging from 19-34 Gy and shown to be comparable with regard to primary tumor control compared to multi-fractionated regimens (49-53). This observation, as well as the possibility that at longer follow-up outcomes are preferentially affected by competing comorbidities in the inoperable population, was the foundation for NRG Oncology RTOG 0915 (Sep 2009-Mar 2011) (54). Eighty-four patients were randomized between a single-fraction (34 Gy in 1 fraction; $\mathrm{n}=39$ ) or multi-fraction (48 Gy in 4 fractions; $\mathrm{n}=45$ ) SBRT regimen to determine the optimum dosing that would yield the least chance of grade $3+$ toxicity for equivalent cancerrelated control in medically inoperable patients. Tissue density heterogeneity corrections were required for dose planning. With a median follow-up of 30.2 months, rates of grade $3+$ protocol-specific adverse events were $10.3 \%$ and $13.3 \%$, respectively, for single- and multiple-fraction arms. Primary tumor control was excellent for both arms $(97.0 \%$ vs. $92.7 \%)$. There was a trend toward improved 2-year OS and disease-free survival with the multiple fraction $\operatorname{arm}(61.3 \%$ vs. $77.7 \%$ and $56.4 \%$ vs. $71.1 \%$, respectively). However, the study was not powered to adequately evaluate these endpoints and these did not reach statistical significance. Consequently, 34 Gy in 1 fraction was the recommended arm for further study (55).

In addition, the results of a randomized phase II clinical trial at Roswell Park Cancer Institute (Sep 2008-Apr 2015) comparing $30 \mathrm{~Gy}$ in one fraction vs. 60 Gy in 3 fractions (without heterogeneity corrections) were recently reported. Rates of grade $3+$ adverse events were comparable between the arms $(27 \%$ and $33 \%$ of patients on the single- and multifraction arms respectively) and there was no statistically significant difference in OS $(71 \%$ vs. $61 \%, \mathrm{P}=0.44)$ or progression-free survival ( $63 \%$ vs. $51 \%, \mathrm{P}=0.99)$ (56).

In addition, a Roswell Park retrospective analysis of 42 patients treated with central lung tumors within $2 \mathrm{~cm}$ of the proximal bronchial tree showed no difference in OS, progression-free survival, local failure, nodal failure, or distant failure at 18 months between patients treated with 26-30 Gy in 1 fraction vs those treated with 52.6-60 Gy in 5 fractions. Although the single-fraction cohort had higher cumulative incidence of grade 3+ toxicity, univariate analysis did not identify dose as a significant factor for increased risk of grade 3+ toxicity (57).

Both of the aforementioned 30- and 34-Gy regimens have been shown to be equally safe, efficacious, and with minimal toxicity (58). Thus, in appropriately selected patients, it appears such single-fraction regimens are reasonable alternatives to more fractionated treatments. 
Table 2 Select studies evaluating the toxicity of treatment on consecutive and/or nonconsecutive days

\begin{tabular}{|c|c|c|c|c|c|}
\hline Study & $\mathrm{n}$ & Follow up & Dose & Fractionation & G2+ toxicity (\%) \\
\hline Stauder et al. (59), 2011 & & & 48 Gy/4 fx (central) & Consecutive & 14.6 \\
\hline Song et al. (60), 2009 & 32 & $26.5 \mathrm{mo}$ & 40-60 Gy/3-4 fx (central) & Consecutive & $33^{\star}$ \\
\hline Jain et al. (61), 2013 & 54 & $4 \mathrm{mo}$ & $48 \mathrm{~Gy} / 4 \mathrm{fx}(\leq 3 \mathrm{~cm}$ tumor $)$ & Consecutive & 55.6 \\
\hline \multirow[t]{2}{*}{ Verma et al. (62), 2017} & 92 & $12 \mathrm{mo}$ & $48-60$ Gy/3-5 fx ( $\geq 5 \mathrm{~cm}$ tumors) & Consecutive & 43 \\
\hline & & & & Nonconsecutive & 7 \\
\hline \multirow[t]{2}{*}{ Alite (63), 2016} & 107 & $3 y$ & 50 or $60 \mathrm{~Gy} / 5 \mathrm{fx}$ & Consecutive & 35 \\
\hline & & & & Nonconsecutive & 35.8 \\
\hline
\end{tabular}

*, rate of grade 3+ pulmonary toxicity. y, years; mo, months; $n$, number of patients evaluated; G2+, grade 2+; fx, fractions.

\section{Consecutive vs. non-consecutive fractionation}

There is some inconsistency in the literature regarding the relative safety of SBRT administered in daily (consecutive) $v s$. non-consecutive fractions (Table 2) and this is reflected by modern trial protocols, some of which require a minimum of $40 \mathrm{~h}$ between fractions $(64,65)$ and some of which permit or require daily treatment $(54,66)$. A prospective study from Mayo Clinic showed acceptable rates (12.5-14.3\%) of grade $2+$ pneumonitis in 84 patients with central or peripheral lung tumors treated in 3 or 4 consecutive daily fractions (59). However, a separate study showed 8 of 9 patients with central lung tumors treated with 40-60 Gy in 3-4 daily fractions developed bronchial strictures and 3 patients $(33 \%)$ developed grade $3+$ pulmonary toxicity (60). Results of a randomized prospective study suggest increased grade $2+$ acute toxicity in patients receiving 4-fraction SBRT daily compared to receiving SBRT on non-consecutive days (61). More recently, a multi-institutional analysis evaluating toxicity in patients with tumors $>5 \mathrm{~cm}$ showed grade $2+$ toxicities of $7 \%$ vs. $43 \%$ between non-consecutive $(\mathrm{n}=46)$ and daily ( $\mathrm{n}=46)$ treatment groups respectively, a finding attributed to interfractional normal tissue repair in the former group (62).

Fractionation scheme has also been suggested to influence treatment efficacy. A recent study retrospectively evaluated the LC of tumors treated on consecutive $v s$. nonconsecutive days on the basis that differences in treatment timing may exploit re-oxygenation kinetics and promote radiosensitivity. One hundred ninety-two patients who received 50 or 60 Gy in 5 fractions were stratified between those who did and did not get treated daily. There were 18 failures in the entire cohort (15.4\%) with 14 of these in the group treated consecutively and 4 treated nonconsecutively. Propensity matching yielded 3-year LC rates of $97.5 \%$ and $63.6 \%$ for non-consecutively and consecutively treated patients, respectively (63). This finding requires validation in larger independent cohorts and prospective trials.

\section{Patterns of failure}

In one of the largest patterns of failure studies to date, Senthi et al. retrospectively analyzed the patterns of recurrence for 676 patients treated with SBRT for early-stage NSCLC. With a median follow up of 32.9 months, there were 124 recurrences and actuarial 5-year local, regional, and distant recurrences were $10.5 \%, 12.7 \%$, and $19.9 \%$ respectively. Nearly half (46\%) of the recurrences were isolated distant recurrences that occurred at a median of 8.3 months after treatment, suggesting existing subclinical disease undisclosed by baseline ${ }^{18} \mathrm{~F}$-FDG-PET imaging that was required for study inclusion. Roughly one-third of recurrences were isolated locoregional and thus potentially amenable to salvage therapy. Given a combined recurrence and second primary event rate of $6 \%$ per patient per 6 months for the first 3 years and $1 \%$ for the subsequent 2 years, the authors suggested a follow up of 6-month CT scans for the first 3 years after SBRT (67). This theme of excellent LC and distant-predominant recurrence has been echoed across multiple retrospective studies $(43,68,69)$, prospective studies $(26,28,66,69)$, and a systematic review (70). 


\section{SBRT for tumors greater than $5 \mathrm{~cm}$}

Patients with large $(>5 \mathrm{~cm})$ tumors are underrepresented in SBRT data in part due to the relative infrequency of large, lymph node-negative disease, and concern for significant toxicity with larger volumes. Multiple studies have evaluated the effect of size on local, regional, and distant recurrence and their conclusions are mixed in this regard. Moreover, they evaluate a relatively small proportion of tumors $\geq 5 \mathrm{~cm}$ (71-76). The first single-institution study specifically addressing this population evaluated outcomes after SBRT for 40 patients. Eighteen-month LC, locoregional control, disease-free survival, and OS were 91.2\%, 64.4\%, 34.6\%, and $59.7 \%$ respectively. Failures were predominantly distant $(32.5 \%)$ and the rate of grade $3+$ toxicity was acceptable at $7.5 \%(77)$.

In the largest multi-institutional study evaluating this population to date, 92 patients, nearly half of which received 50 Gy in 5 fractions, were retrospectively analyzed from 12 institutions. Actuarial 1- and 2-year LC rates were 95.7\% and $73.2 \%$, respectively and grade $3+$ toxicity occurred in $11 \%$ of patients, suggesting relative efficacy and safety of SBRT in this population at high risk of recurrence. Distant metastases, the predominant mode of failure, occurred in $21 \%$ of patients at a median follow up of 8 months (78).

This higher propensity of large tumors for distant recurrence is in accordance with a recent National Cancer Database (NCDB) analysis showing survival benefit of large-tumor SBRT patients who received chemotherapy (median OS 30.6 vs. 23.4 months) (79), congruent with findings of surgical studies $(80,81)$. Although the NCDB lacks cancer-specific survival endpoints, there is data to suggest benefit in disease-free survival with addition of chemotherapy selectively added for large tumors after SBRT (70). Thus, it appears that modern SBRT dosing regimens are sufficient to achieve adequate LC in large tumors, with acceptable toxicity. Addressing subclinical distant disease through systemic therapy in this at-risk population may be more pertinent than local dose-escalation.

\section{SBRT vs, conventionally fractionated radiotherapy}

Although the body of evidence in support of SBRT for inoperable patients is extensive, resulting in its adoption as standard of care $(22,23)$, this acceptance came without randomized evidence to support its superiority to conventionally fractionated radiotherapy. This changed with the recent conclusion of SPACE, a Scandinavian phase II randomized trial of 102 patients comparing SBRT, 66 Gy in 3 fractions, $v s$. conventionally fractionated radiotherapy [threedimensional conformal radiotherapy (3DCRT)], 70 Gy in 35 fractions, in medically inoperable patients with Stage I NSCLC. There was no difference in progression-free survival or OS between the two arms, despite a tendency toward improved disease control rate with SBRT. However, patients treated with 3DCRT experienced worse dyspnea, chest pain, and cough on quality of life (QOL) analysis, although overall toxicity was mild (mostly grade $1-2$ ) in both treatment groups (82). It is notable that with low toxicity and a 3 -year OS of nearly $60 \%$, the results of the 3DCRT arm are improved when compared to historical data, likely a function of improved staging and treatment in the past 1-2 decades (11). The authors concluded that SBRT should be the standard treatment for inoperable Stage I NSCLC patients since it is more convenient with less toxicity and improved QOL.

There are two other ongoing randomized trials evaluating similar regimens. The Trans-Tasman Radiation Oncology Group (TROG) 0902 (CHISEL) Australian/ New Zealand study, recently closed to accrual with a sample size of 100 patients, compares SBRT $(18 \mathrm{~Gy} \times 3$ or $12 \mathrm{~Gy} \times 4$ ) with external beam radiation therapy delivered in 66 Gy in 33 fractions or 50 Gy in 20 fractions (83). The Canadian phase III randomized trial LUSTRE entails 2:1 randomization to either SBRT (48 Gy in 4 fractions for peripheral lesions; 60 Gy in 8 fractions for central lesions) or conventionally hypofractionated radiotherapy (CRT) of 60 Gy in 15 fractions. The comparison to hypofractionated CRT, which is standard Canadian practice, and inclusion of central tumors is unique compared to the aforementioned studies. Accrual is expected to be complete in 3 years (84). These studies may help to address remaining concerns regarding the efficacy and safety of SBRT compared with more conventional or hypofractionated radiation treatment schedules.

\section{SBRT in operable patients}

Although SBRT has become standard of care in medically inoperable patients $(22,23)$, the role of SBRT in operable patients is less defined (Table 3). RTOG 0618 was the first prospective evaluation of the feasibility of SBRT in operable patients, using the dosing established from RTOG 0236 (18 Gy $\times 3)$. Early data shows promising 2-year primary tumor failure, local failure, and OS rates of $7.7 \%$, 
Table 3 Studies comparing SBRT to lobectomy

\begin{tabular}{|c|c|c|c|c|c|c|c|c|c|c|c|c|}
\hline Study & $\mathrm{n}$ & $\begin{array}{c}\text { Follow } \\
\text { up }\end{array}$ & \multicolumn{2}{|c|}{ Local failure (\%) } & \multicolumn{2}{|c|}{ Regional failure (\%) } & \multicolumn{2}{|c|}{ Distant failure (\%) } & \multicolumn{2}{|c|}{ Disease-free survival (\%) } & \multicolumn{2}{|c|}{ OS (\%) } \\
\hline $\begin{array}{l}\text { RTOG } 0618 \\
\text { (85), } 2013\end{array}$ & 26 & $2 y$ & - & 19.2 & - & 11.7 & - & 15.4 & - & 65.4 & - & 84.4 \\
\hline $\begin{array}{l}\text { JCOG } 04013 \\
(66), 2015\end{array}$ & $65^{\star}$ & $3 y$ & - & 85.4 & - & 25 & - & 33 & - & 54.5 & - & 76.5 \\
\hline $\begin{array}{l}\text { Verstegen et al. } \\
(87), 2013\end{array}$ & 128 & $3 y$ & 3.1 & 1.6 & 9.4 & 4.7 & 34.5 & 14.8 & 79.7 & 75 & 76.9 & 79.6 \\
\hline $\begin{array}{l}\text { Grills et al. } \\
\text { (88), } 2017\end{array}$ & 254 & $5 y$ & 5 & 8 & 5 & 18 & 12 & 11 & 72 & 53 & 78 & 61 \\
\hline $\begin{array}{l}\text { Yu et al. (90), } \\
2015\end{array}$ & 1,078 & $1 \mathrm{y}$ & - & - & - & - & - & - & - & - & 73.9 & 69.7 \\
\hline $\begin{array}{l}\text { Chang et al. } \\
\text { (91), } 2015\end{array}$ & 58 & $3 y$ & 0 & 4 & 4 & 10 & 9 & 3 & 80 & 86 & 79 & 95 \\
\hline
\end{tabular}

*, number of operable patients evaluated on the trial; ${ }^{\dagger}$, number of patients included in matched analysis that included SBRT patients who were offered lobectomy but refused; ${ }^{\ddagger}$, number of patients treated with either lobectomy or SBRT. y, years; $n$, number of patients evaluated. SBRT, stereotactic body radiation therapy.

$19.2 \%$, and $84.4 \%$, respectively (85). A second Japanese study, JCOG 04013, shows similar 3-year OS of 76.5\%, comparing favorably to historical surgical results (66).

In a 2016 NCDB analysis that included only patients free of comorbidities, 13,562 stage I lung cancer patients treated with lobectomy were compared to 1781 patients treated with SBRT. Propensity-matched analysis revealed a 5 -year OS of $59 \%$ for lobectomy vs. $29 \%$ for SBRT (86). This is in contrast to a Dutch propensity-matched analysis of 64 SABR and 64 video-assisted thoracoscopic surgery (VATS) lobectomy patients, which showed superior 3-year locoregional control with SABR $(93.3 \%$ vs. $82.6 \%)$ with no difference in distant recurrence or OS (87). Contrarily, recent data from a single institution shows higher rates of regional and clinical failure in SBRT compared to lobectomy with lower disease-free and OS, despite similar rates of local recurrence and distant metastasis (88).

In a Surveillance, Epidemiology, and End Results (SEER) analysis of patients over 65 years of age, 9,093 patients were analyzed and split into cohorts receiving lobectomy $(\mathrm{n}=7,215)$, sublobar resection $(\mathrm{n}=1,496)$, and SABR $(\mathrm{n}=382)$. OS was determined to be time-dependent using proportional hazards regression, with SABR associated with better survival within the first 6 months after diagnosis [adjusted hazard ratio (AHR) 0.45] but worse survival after 6 months (AHR 1.66). Propensity score matching of SABR and lobectomy cohorts, which accounted for comorbidities, yielded similar OS in both groups (89). In addition, the authors concluded that the clinical relevance of these findings are confined to the patients well-represented by the matched cohorts (i.e., those with advanced age and multiple comorbidities) and cannot be used to justify the use of SABR over surgery in operable patients. A subsequent propensity-matched SEER analysis in a similar cohort of patients found a significantly lower rate of acute toxicity and early mortality in patients receiving SBRT with no difference in toxicity and higher mortality with SBRT at 24 months. Furthermore, overall mortality was significantly worse with SBRT for patients with longer life expectancy (>5 years), whereas it was equivalent with shorter life expectancies (90). These findings indicate the importance of longitudinal analysis when comparing these modalities as well as the risk of competing comorbidities when selecting the most appropriate treatment modality. 
To date, there have been 3 randomized control trials comparing surgery $v s$. SBRT in operable patients (ROSEL, STARS, RTOG 1021/ACOSOG Z4099), all of which have closed due to poor accrual (92). Despite this, a pooled analysis of patients from the STARS and ROSEL trials offers potential insight. In this analysis, a total of 58 patients were analyzed with an estimated 3 -year OS of $95 \%$ for SABR vs. $79 \%$ for lobectomy, with a median follow-up of 40.2 months for the SBRT group and 35.4 months for the surgery group. Although this marked difference should be interpreted with caution given the small patient sample, these results suggest a large, randomized comparison between SBRT and lobectomy is warranted (91).

To our knowledge, three phase III studies to answer this question are currently underway, the United States STABLE-MATES trial (93), the U.K. SABRTooth trial (94), and the Veterans Affairs VALOR trial (95). Of these, only the STABLE-MATES trial compares SBRT with sublobar resection (instead of lobectomy). This trial utilizes randomization prior to trial enrollment and also has an observational cohort if patients decline their treatment assignment but elect to be observed after surgery (93). These methods are designed to circumvent the difficulties of accruing patients to disparate treatment modalities. These trials will hopefully provide much needed insight into this ongoing debate.

\section{Particle therapy}

Given the emergence of proton therapy and data suggesting efficacy in hypofractionated regimens in the treatment of NSCLC (96-98), it is not surprising that there have been attempts to utilize proton therapy using modern SBRT fractionation schemes due to theoretically higher dose conformity and reduction of radiation dose to normal tissue $(99,100)$. Virtual studies suggest a benefit in proton SBRT, in particular intensity-modulated proton therapy (IMPT), in reducing lung dose as well as dose to other critical structures including the aorta, brachial plexus, heart, pulmonary vessels, and spinal cord in the treatment of centrally or superiorly located stage I NSCLC tumors (101). Early data from Massachusetts General Hospital involving 15 patients shows such treatment is well-tolerated in patients with adverse factors such as pulmonary comorbidities, prior chest irradiation, or multiple primary tumors. Furthermore, this study also suggested proton therapy was efficacious, with a 2-year LC of $100 \%$ (102).

Carbon ions share the advantageous Bragg peak of protons while having the additional benefit of higher linear energy transfer, potentially resulting in significantly higher BED (103). Dosimetrically, carbon ion planning can achieve significantly lower conformity index and lung dose compared to photon SBRT in 4-fraction treatment (104). A recent phase I dose-escalation trial evaluating feasibility of single-fraction treatment of peripheral Stage I NSCLC showed 5-year LC of 95\% with doses of 48-50 Gy [relative biological effectiveness (RBE)] as well as no grade 3 or higher toxicities (105). A relatively larger study entailing proton $(n=43)$ or carbon ion $(n=27)$ treatment of 70 patients with T2 tumors, showed that 4-year OS, LC, and progression-free survival (PFS) rates were $58 \%, 75 \%$, and $46 \%$ respectively, with grade 3 pulmonary toxicity observed in only 2 patients. The majority of these patients were treated with either 4 -fraction $(n=16)$ or 10 -fraction $(n=36)$ regimens (106).

While reimbursement uncertainty and technical complexity of charged particles has limited their use in many institutions (107-109), these data suggest that in situations that demand maximal tissue sparing or entail larger tumors in difficult locations, proton or carbon ion therapy are viable modalities worth consideration at equipped centers. Ultimately, prospective trials will be required to validate their relative efficacy and safety compared to historical photon data.

\section{Histologic and molecular predictors of treatment response}

Thus far, clinically utilized risk-adapted dosing strategies have primarily accounted for tumor location and size. However, recent evidence suggests heterogeneity in tumor response depends on tumor subtype. Recent studies have shown a significantly higher local failure rate for squamous cell cancers over adenocarcinomas as well as other NSCLCs $(88,110,111)$. Another study showed that heterogeneity exists even within adenocarcinomas, with micropapillary and solid subtypes correlating with higher rates of locoregional and distant failure (112).

Advances in cancer genomics have led to the discovery of the prognostic and therapeutic significance of $\mathrm{v}-\mathrm{Ki}$-ras 2 Kirsten rat sarcoma viral oncogene homolog $(K R A S)$ and epidermal growth factor receptor (EGFR) mutations in the setting of metastatic adenocarcinoma (113-116). Recently, such genomic data is being integrated into studies involving early-stage tumors. In one study of 75 patients treated with SBRT $(18$ Gy $\times 3$ or $10-12$ Gy $\times 5$ ), although histology 
was not clearly associated with recurrence, the presence of KRAS mutation was associated with significantly lower freedom from recurrence ( $48 \%$ vs. $69 \%$ ) and decreased cancer-specific survival ( $75 \%$ vs. $93 \%$ ) when compared to $K R A S$-wildtype tumors or those with unknown mutation status (117). Similarly, a recent study implicates Kelch ECH associating protein 1/nuclear factor erythroid 2-related factor 2 (KEAP1/NRF2) mutations in promoting radioresistance and local recurrence after radiotherapy for lung squamous cell carcinomas. Of a cohort of 42 patients that were studied, the majority had stage I-II tumors (81\%) and received treatment with SABR (74\%). The incidence of local failure at 30 months was $70 \%$ in KEAP1/NRF2mutants $v s .18 \%$ in wildtype tumors. Furthermore, the authors identified Cancer Personalized Profiling by deep Sequencing (CAPP-Seq) analysis of pretreatment plasma as an accurate and noninvasive method to identify KEAP1 mutation. This testing was utilized to verify the association of KEAP1 and local recurrence in an independent cohort of 20 patients. These results imply a potential benefit of $\mathrm{KEAP} 1 / \mathrm{NRF} 2$ testing in identifying patients more prone to local recurrence after SBRT (118).

\section{Conclusions}

SBRT is the standard of care for the medically inoperable patient with early-stage NSCLC (22-24) and is at least equivalent to conventionally fractionated radiotherapy in this setting (82). SBRT may be a reasonable alternative to surgery in operable patients, although its appropriateness in this context must be further elucidated by ongoing randomized trials (93-95).

As the modality has evolved, the variability in institutional practices has led to a diverse assortment of fractionation schemes. SBRT has been shown to be efficacious with these regimens, particularly if treatment achieves a defined level of dose-intensity (43). Similarly, SBRT can be delivered safely regardless of location $(30,32,33)$, although an important factor in selecting the most appropriate regimen is tumor location with regard to proximity to organs at risk, especially in the case of tumors in close proximity to or abutting mediastinal structures $(31,37,39,40)$. Particularly in such cases, regimens that offer adequate LC with minimal toxicity are best and may entail more protracted fractionation in order to achieve dosimetric objectives $(35,36,38)$. For the appropriately selected patient, a single-fraction regimen may be a reasonable, convenient option in achieving good LC with minimal toxicity (55-57).
There are other potential ways to optimize toxicity profile. For example, treatment on nonconsecutive days, rather than daily, is potentially beneficial in reducing toxicity $(61,62)$. Whether non-consecutive fractionation results in improved disease control needs further evaluation (63). Technological advances in the form of proton or carbon ion therapy may be beneficial in the treatment of higher risk patients, such as those with cardiopulmonary comorbidities or prior thoracic irradiation, for whom maximal dose conformity is warranted to prevent excess toxicity $(102,106)$.

Despite the excellent LC achieved by modern SBRT fractionation regimens, distant recurrence remains the primary mode of failure after treatment (70), likely a result of occult metastatic disease not revealed by pretreatment imaging. This is especially true of larger tumors $(>5 \mathrm{~cm})$ and warrants evaluation of integrating systemic therapy into treatment regimens for such patients (77-79). Furthermore, as SBRT becomes increasingly individualized in tandem with advances in cancer genomics and molecular profiling, histo-molecular classification of early-stage NSCLC may provide valuable predictive information in tailoring treatment and follow up $(110,112,117,118)$.

\section{Acknowledgements}

None.

\section{Footnote}

Conflicts of Interest: The authors have no conflicts of interest to declare.

\section{References}

1. Hu SS, Neff L, Agaku IT, et al. Tobacco Product Use Among Adults - United States, 2013-2014. MMWR Morb Mortal Wkly Rep 2016;65:685-91.

2. Siegel RL, Miller KD, Jemal A. Cancer statistics, 2017. CA Cancer J Clin 2017;67:7-30.

3. Shields TW. Surgical therapy for carcinoma of the lung. Clin Chest Med 1982;3:369-87.

4. Mountain CF. Revisions in the International System for Staging Lung Cancer. Chest 1997;111:1710-7.

5. Naruke T, Tsuchiya R, Kondo H, et al. Prognosis and survival after resection for bronchogenic carcinoma based on the 1997 TNM-staging classification: the Japanese experience. Ann Thorac Surg 2001;71:1759-64.

6. Flehinger BJ. The Effect of Surgical Treatment on Survival 
from Early Lung Cancer. Chest 1992;101:1013-18.

7. Ginsberg RJ, Rubinstein LV, Group LCS, et al. Randomized trial of lobectomy versus limited resection for T1 N0 non-small cell lung cancer. Ann Thorac Surg 1995;60:615-22.

8. Dosoretz DE, Katin MJ, Blitzer PH, et al. Radiation therapy in the management of medically inoperable carcinoma of the lung: results and implications for future treatment strategies. Int J Radiat Oncol Biol Phys 1992;24:3-9.

9. Sibley GS, Jamieson TA, Marks LB, et al. Radiotherapy alone for medically inoperable stage I non-small-cell lung cancer: the Duke experience. Int J Radiat Oncol Biol Phys 1998;40:149-54.

10. Zierhut D, Bettscheider C, Schubert K, et al. Radiation therapy of stage I and II non-small cell lung cancer (NSCLC). Lung Cancer 2001;34:S39-43.

11. Qiao X, Tullgren O, Lax I, et al. The role of radiotherapy in treatment of stage I non-small cell lung cancer. Lung Cancer 2003;41:1-11.

12. Zhang HX, Yin WB, Zhang LJ, et al. Curative radiotherapy of early operable non-small cell lung cancer. Radiother Oncol 1989;14:89-94.

13. Kaskowitz L, Graham MV, Emami B, et al. Radiation therapy alone for stage I non-small cell lung cancer. Int J Radiat Oncol Biol Phys 1993;27:517-23.

14. Cox JD, Azarnia N, Byhardt RW, et al. A randomized phase I/II trial of hyperfractionated radiation therapy with total doses of $60.0 \mathrm{~Gy}$ to $79.2 \mathrm{~Gy}$ : possible survival benefit with greater than or equal to 69.6 Gy in favorable patients with Radiation Therapy Oncology Group stage III nonsmall-cell lung carcinoma: report of Radiation Therapy Oncology Group 83-11. J Clin Oncol 1990;8:1543-55.

15. Kong FM, Ten Haken RK, Schipper MJ, et al. High-dose radiation improved local tumor control and overall survival in patients with inoperable/unresectable non-small-cell lung cancer: Long-term results of a radiation dose escalation study. Int J Radiat Oncol Biol Phys 2005;63:324-33.

16. Chen M, Hayman JA, Ten Haken RK, et al. Longterm results of high-dose conformal radiotherapy for patients with medically inoperable T1-3N0 non-smallcell lung cancer: Is low incidence of regional failure due to incidental nodal irradiation? Int J Radiat Oncol Biol Phys 2006;64:120-6.

17. Slotman BJ, Hian Njo K, Karim ABMF. Curative radiotherapy for technically operable stage I nonsmall cell lung cancer. Int J Radiat Oncol Biol Phys 1994;29:33-7.

18. Sandler HM, Curran WJ, Turrisi AT. The influence of tumor size and pre-treatment staging on outcome following radiation therapy alone for stage I non-small cell lung cancer. Int J Radiat Oncol Biol Phys 1990;19:9-13.

19. Blomgren H, Lax I, Göranson H, et al. Radiosurgery for Tumors in the Body: Clinical Experience Using a New Method. J Radiosurgery 1998;1:63-74.

20. Nagata Y, Matsuo Y, Takayama K, et al. Current status of stereotactic body radiotherapy for lung cancer. Int J Clin Oncol 2007;12:3-7.

21. Song DY, Kavanagh BD, Benedict SH, et al. Stereotactic body radiation therapy. Rationale, techniques, applications, and optimization. Oncol. Williston Park N 2004;18:14191430; discussion 1430, 1432, 1435-6.

22. Ettinger DS, Wood DE, Aisner DL, et al. Non-Small Cell Lung Cancer, Version 5.2017, NCCN Clinical Practice Guidelines in Oncology. J Natl Compr Canc Netw 2017;15:504-35.

23. Postmus PE, Kerr KM, Oudkerk M, et al. Early and locally advanced non-small-cell lung cancer (NSCLC): ESMO Clinical Practice Guidelines for diagnosis, treatment and follow-up†. Ann Oncol 2017;28:iv1-iv21.

24. Videtic GMM, Donington J, Giuliani M, et al. Stereotactic body radiation therapy for early-stage non-small cell lung cancer: Executive Summary of an ASTRO Evidence-Based Guideline. Pract Radiat Oncol 2017;7:295-301.

25. McGarry RC, Papiez L, Williams M, et al. Stereotactic body radiation therapy of early-stage non-small-cell lung carcinoma: Phase I study. Int J Radiat Oncol Biol Phys 2005;63:1010-5.

26. Baumann P, Nyman J, Hoyer M, et al. Outcome in a Prospective Phase II Trial of Medically Inoperable Stage I Non-Small-Cell Lung Cancer Patients Treated With Stereotactic Body Radiotherapy. J Clin Oncol 2009;27:3290-6.

27. Timmerman R, McGarry R, Yiannoutsos C, et al. Excessive Toxicity When Treating Central Tumors in a Phase II Study of Stereotactic Body Radiation Therapy for Medically Inoperable Early-Stage Lung Cancer. J Clin Oncol 2006;24:4833-9.

28. Timmerman R, Paulus R, Galvin J, et al. Stereotactic Body Radiation Therapy for Inoperable Early Stage Lung Cancer. JAMA 2010;303:1070-6.

29. Timmerman RD, Hu C, Michalski J, et al. Long-term Results of RTOG 0236: A Phase II Trial of Stereotactic Body Radiation Therapy (SBRT) in the Treatment of Patients with Medically Inoperable Stage I Non-Small Cell Lung Cancer. Int J Radiat Oncol Biol Phys 2014;90:S30.

30. Bezjak A, Paulus R, Gaspar LE, et al. Efficacy and 
Toxicity Analysis of NRG Oncology/RTOG 0813 Trial of Stereotactic Body Radiation Therapy (SBRT) for Centrally Located Non-Small Cell Lung Cancer (NSCLC). Int J Radiat Oncol Biol Phys 2016;96:S8.

31. Lindberg K, Bergström P, Brustugun OT, et al. OA24.05 The Nordic HILUS-Trial - First Report of a Phase II Trial of SBRT of Centrally Located Lung Tumors. J Thorac Oncol 2017;12:S340.

32. Chang JY, Balter PA, Dong L, et al. Stereotactic Body Radiation Therapy in Centrally and Superiorly Located Stage I or Isolated Recurrent Non-Small-Cell Lung Cancer. Int J Radiat Oncol Biol Phys 2008;72:967-71.

33. Haasbeek CJA, Lagerwaard FJ, Slotman BJ, et al. Outcomes of Stereotactic Ablative Radiotherapy for Centrally Located Early-Stage Lung Cancer. J Thorac Oncol 2011;6:2036-43.

34. Chaudhuri AA, Tang C, Binkley MS, et al. Stereotactic ablative radiotherapy (SABR) for treatment of central and ultra-central lung tumors. Lung Cancer 2015;89:50-6.

35. Li Q, Swanick CW, Allen PK, et al. Stereotactic ablative radiotherapy (SABR) using 70Gy in 10 fractions for nonsmall cell lung cancer: Exploration of clinical indications. Radiother Oncol 2014;112:256-61.

36. Tekatli H, Haasbeek N, Dahele M, et al. Outcomes of Hypofractionated High-Dose Radiotherapy in Poor-Risk Patients with "Ultracentral" Non-Small Cell Lung Cancer. J Thorac Oncol 2016;11:1081-9.

37. Stam B, Grills IS, Kwint M, et al. SBRT for Central Tumors in Early Stage NSCLC Patients. Int J Radiat Oncol Biol Phys 2017;99:S17.

38. Daly M, Novak J, Monjazeb A. P2.05-056 Safety of Stereotactic Body Radiotherapy for Central, Ultracentral, and Paramediastinal Lung Tumors. J Thorac Oncol 2017;12:S1066.

39. Haseltine JM, Rimner A, Gelblum DY, et al. Fatal complications after stereotactic body radiation therapy for central lung tumors abutting the proximal bronchial tree. Pract Radiat Oncol 2016;6:e27-e33.

40. Corradetti MN, Haas AR, Rengan R. Central-airway necrosis after stereotactic body-radiation therapy. N Engl J Med 2012;366:2327-9.

41. Timmerman RD, Kavanagh BD, Cho LC, et al. Stereotactic Body Radiation Therapy in Multiple Organ Sites. J Clin Oncol 2007;25:947-52.

42. Wulf J, Baier K, Mueller G, et al. Dose-response in stereotactic irradiation of lung tumors. Radiother Oncol 2005;77:83-7.

43. Onishi H, Shirato H, Nagata Y, et al. Hypofractionated
Stereotactic Radiotherapy (HypoFXSRT) for Stage I Nonsmall Cell Lung Cancer: Updated Results of 257 Patients in a Japanese Multi-institutional Study. J Thorac Oncol 2007;2:S94-S100.

44. Onimaru R, Fujino M, Yamazaki K, et al. Steep DoseResponse Relationship for Stage I Non-Small-Cell Lung Cancer Using Hypofractionated High-Dose Irradiation by Real-Time Tumor-Tracking Radiotherapy. Int J Radiat Oncol Biol Phys 2008;70:374-81.

45. Guckenberger M, Wulf J, Mueller G, et al. DoseResponse Relationship for Image-Guided Stereotactic Body Radiotherapy of Pulmonary Tumors: Relevance of 4D Dose Calculation. Int J Radiat Oncol Biol Phys 2009;74:47-54.

46. Park C, Papiez L, Zhang S, et al. Universal Survival Curve and Single Fraction Equivalent Dose: Useful Tools in Understanding Potency of Ablative Radiotherapy. Int J Radiat Oncol Biol Phys 2008;70:847-52.

47. Brown JM, Diehn M, Loo BW. Stereotactic ablative radiotherapy should be combined with a hypoxic cell radiosensitizer. Int J Radiat Oncol Biol Phys 2010;78:323-7.

48. Trakul N, Chang CN, Harris J, et al. Tumor VolumeAdapted Dosing in Stereotactic Ablative Radiotherapy of Lung Tumors. Int J Radiat Oncol Biol Phys 2012;84:231-7.

49. Wulf J, Haedinger U, Oppitz U, et al. Stereotactic radiotherapy for primary lung cancer and pulmonary metastases: A noninvasive treatment approach in medically inoperable patients. Int J Radiat Oncol Biol Phys 2004;60:186-96.

50. Whyte RI, Crownover R, Murphy MJ, et al. Stereotactic radiosurgery for lung tumors: preliminary report of a phase I trial. Ann Thorac Surg 2003;75:1097-101.

51. Fritz P, Kraus H-J, Mühlnickel W, et al. Stereotactic, single-dose irradiation of stage I non-small cell lung cancer and lung metastases. Radiat Oncol 2006;1:30.

52. Hof H, Muenter M, Oetzel D, et al. Stereotactic singledose radiotherapy (radiosurgery) of early stage nonsmallcell lung cancer (NSCLC). Cancer 2007;110:148-55.

53. Hara R, Itami J, Kondo T, et al. Clinical outcomes of single-fraction stereotactic radiation therapy of lung tumors. Cancer 2006;106:1347-52.

54. Anon. Radiation Therapy Oncology Group 0915. A Randomized Phase II Study Comparing 2 Stereotactic Body Radiation Therapy (SBRT) Schedules for Medically Inoperable Patients with Stage I Peripheral NonSmall Cell Lung Cancer. Available online: https://www. rtog.org/ClinicalTrials/ProtocolTable/StudyDetails. aspx? study=0915 
55. Videtic GM, Hu C, Singh AK, et al. A Randomized Phase 2 Study Comparing 2 Stereotactic Body Radiation Therapy Schedules for Medically Inoperable Patients With Stage I Peripheral Non-Small Cell Lung Cancer: NRG Oncology RTOG 0915 (NCCTG N0927). Int J Radiat Oncol Biol Phys 2015;93:757-64.

56. Singh AK, Suescun JAG, Stephans KL, et al. A Phase 2 Randomized Study of 2 Stereotactic Body Radiation Therapy Regimens for Medically Inoperable Patients With Node-Negative, Peripheral Non-Small Cell Lung Cancer. Int J Radiat Oncol Biol Phys 2017;98:221-2.

57. Ma SJ, Syed Y, Rivers C, et al. P1.05-033 Comparison of Single- and Five-Fraction Schedules of Stereotactic Body Radiation Therapy for Central Lung Tumors. J Thorac Oncol 2017;12:S634.

58. Videtic GMM, Stephans KL, Woody NM, et al. 30 Gy or 34 Gy? Comparing 2 Single-Fraction SBRT Dose Schedules for Stage I Medically Inoperable NonSmall Cell Lung Cancer. Int J Radiat Oncol Biol Phys 2014;90:203-8.

59. Stauder MC, Macdonald OK, Olivier KR, et al. Early pulmonary toxicity following lung stereotactic body radiation therapy delivered in consecutive daily fractions. Radiother Oncol 2011;99:166-71.

60. Song SY, Choi W, Shin SS, et al. Fractionated stereotactic body radiation therapy for medically inoperable stage I lung cancer adjacent to central large bronchus. Lung Cancer 2009;66:89-93.

61. Jain S, Poon I, Soliman H, et al. Lung stereotactic body radiation therapy (SBRT) delivered over 4 or 11days: A comparison of acute toxicity and quality of life. Radiother Oncol 2013;108:320-25.

62. Verma V, Shostrom VK, Zhen W, et al. Influence of Fractionation Scheme and Tumor Location on Toxicities After Stereotactic Body Radiation Therapy for Large ( $\geq 5$ cm) Non-Small Cell Lung Cancer: A Multi-institutional Analysis. Int J Radiat Oncol Biol Phys 2017;97:778-85.

63. Alite F, Stang K, Balasubramanian N, et al. Local control dependence on consecutive vs. nonconsecutive fractionation in lung stereotactic body radiation therapy. Radiother Oncol 2016;121:9-14.

64. Anon. Radiation Therapy Oncology Group 0236. A Phase II Trial of Stereotactic Body Radiation Therapy (SBRT) in the Treatment of Patients with Medically Inoperable Stage I/II Non-Small Cell Lung Cancer. Available online: https://www.rtog.org/ClinicalTrials/ProtocolTable/ StudyDetails.aspx? study=0236

65. Anon. Radiation Therapy Oncology Group 0813. Seamless phase I/II study of stereotactic lung radiotherapy (SBRT) for early stage, centrally located, nonsmall cell lung cancer (NSCLC) in medically inoperable patients. Available online: https://www.rtog.org/ClinicalTrials/ProtocolTable/ StudyDetails.aspx? study=0813

66. Nagata Y, Hiraoka M, Shibata T, et al. Prospective Trial of Stereotactic Body Radiation Therapy for Both Operable and Inoperable T1N0M0 Non-Small Cell Lung Cancer: Japan Clinical Oncology Group Study JCOG0403. Int J Radiat Oncol Biol Phys 2015;93:989-96.

67. Senthi S, Lagerwaard FJ, Haasbeek CJ, et al. Patterns of disease recurrence after stereotactic ablative radiotherapy for early stage non-small-cell lung cancer: a retrospective analysis. Lancet Oncol 2012;13:802-9.

68. Baumann P, Nyman J, Lax I, et al. Factors important for efficacy of stereotactic body radiotherapy of medically inoperable stage I lung cancer. A retrospective analysis of patients treated in the Nordic countries. Acta Oncol 2006;45:787-95.

69. Aoki M, Hatayama Y, Kawaguchi H, et al. Clinical outcome of stereotactic body radiotherapy for primary and oligometastatic lung tumors: a single institutional study with almost uniform dose with different five treatment schedules. Radiat Oncol Lond Engl 2016;11.

70. Chi A, Liao Z, Nguyen NP, et al. Systemic review of the patterns of failure following stereotactic body radiation therapy in early-stage non-small-cell lung cancer: Clinical implications. Radiother Oncol 2010;94:1-11.

71. Takeda A, Kunieda E, Sanuki N, et al. Dose Distribution Analysis in Stereotactic Body Radiotherapy Using Dynamic Conformal Multiple Arc Therapy. Int J Radiat Oncol Biol Phys 2009;74:363-9.

72. Dunlap NE, Larner JM, Read PW, et al. Size matters: A comparison of T1 and T2 peripheral non-small-cell lung cancers treated with stereotactic body radiation therapy (SBRT). J Thorac Cardiovasc Surg 2010;140:583-9.

73. Nath SK, Sandhu AP, Kim D, et al. Locoregional and distant failure following image-guided stereotactic body radiation for early-stage primary lung cancer. Radiother Oncol 2011;99:12-7.

74. Grills IS, Hope AJ, Guckenberger M, et al. A Collaborative Analysis of Stereotactic Lung Radiotherapy Outcomes for Early-Stage Non-Small-Cell Lung Cancer Using Daily Online Cone-Beam Computed Tomography ImageGuided Radiotherapy. J Thorac Oncol 2012;7:1382-93.

75. Allibhai Z, Taremi M, Bezjak A, et al. The Impact of Tumor Size on Outcomes After Stereotactic Body Radiation Therapy for Medically Inoperable Early-Stage 
Non-Small Cell Lung Cancer. Int J Radiat Oncol Biol Phys 2013;87:1064-70.

76. Cuaron JJ, Yorke ED, Foster A, et al. Stereotactic Body Radiation Therapy for Primary Lung Cancers $>3$ Centimeters. J Thorac Oncol 2013;8:1396-401.

77. Woody NM, Stephans KL, Marwaha G, et al. Stereotactic Body Radiation Therapy for Non-Small Cell Lung Cancer Tumors Greater Than $5 \mathrm{~cm}$ : Safety and Efficacy. Int J Radiat Oncol Biol Phys 2015;92:325-31.

78. Verma V, Shostrom VK, Kumar SS, et al. Multiinstitutional experience of stereotactic body radiotherapy for large ( $\geq 5$ centimeters) non-small cell lung tumors. Cancer 2017;123:688-96.

79. Verma V, McMillan MT, Grover S, et al. Stereotactic Body Radiation Therapy and the Influence of Chemotherapy on Overall Survival for Large ( $\geq 5$ Centimeter) NonSmall Cell Lung Cancer. Int J Radiat Oncol Biol Phys 2017;97:146-54.

80. Pignon J-P, Tribodet H, Scagliotti GV, et al. Lung Adjuvant Cisplatin Evaluation: A Pooled Analysis by the LACE Collaborative Group. J Clin Oncol 2008;26:3552-9.

81. Strauss GM, Herndon JE, Maddaus MA, et al. Adjuvant Paclitaxel Plus Carboplatin Compared With Observation in Stage IB Non-Small-Cell Lung Cancer: CALGB 9633 With the Cancer and Leukemia Group B, Radiation Therapy Oncology Group, and North Central Cancer Treatment Group Study Groups. J Clin Oncol 2008;26:5043-51.

82. Nyman J, Hallqvist A, Lund JA, et al. SPACE-A randomized study of SBRT vs conventional fractionated radiotherapy in medically inoperable stage I NSCLC. Radiother Oncol 2016;121:1-8.

83. Anon. Trans Tasman Oncology Group 09.02. Hypofractionated image guided radiotherapy ("stereotactic") versus conventional radiotherapy for inoperable early stage I non small cell lung cancer (NSCLC). I CHISEL. Available online: http://www. australiancancertrials.gov.au/search-clinical-trials/searchresults/clinical-trials-details.aspx? TrialID $=320898 \& d s=1$

84. Swaminath A, Wierzbicki M, Parpia S, et al. Canadian Phase III Randomized Trial of Stereotactic Body Radiotherapy Versus Conventionally Hypofractionated Radiotherapy for Stage I, Medically Inoperable NonSmall-Cell Lung Cancer - Rationale and Protocol Design for the Ontario Clinical Oncology Group (OCOG)LUSTRE Trial. Clin Lung Cancer 2017;18:250-4.

85. Timmerman RD, Paulus R, Pass HI, et al. Stereotactic body radiation therapy (SBRT) to treat operable early-stage lung cancer patients. J Clin Oncol 2013;31:abstr 7523.

86. Rosen JE, Salazar MC, Wang Z, et al. Lobectomy versus stereotactic body radiotherapy in healthy patients with stage I lung cancer. J Thorac Cardiovasc Surg 2016;152:44-54.e9.

87. Verstegen NE, Oosterhuis JWA, Palma DA, et al. Stage I-II non-small-cell lung cancer treated using either stereotactic ablative radiotherapy (SABR) or lobectomy by video-assisted thoracoscopic surgery (VATS): outcomes of a propensity score-matched analysis. Ann Oncol 2013;24:1543-8.

88. Grills I., Lee Jr. KC, Hymas Jr. RV, et al. Operable Stage I Non-Small Cell Lung Cancer Treated with Stereotactic Radiotherapy (SBRT) Compared to Surgical Lobectomy: Failure Patterns and Implications for Management. Int J Radiat Oncol Biol Phys 2017;99:S17-8.

89. Shirvani SM, Jiang J, Chang JY, et al. Lobectomy, Sublobar Resection, and Stereotactic Ablative Radiotherapy for Early-Stage Non-Small Cell Lung Cancers in the Elderly. JAMA Surg 2014;149:1244.

90. Yu JB, Soulos PR, Cramer LD, et al. Comparative effectiveness of surgery and radiosurgery for stage I nonsmall cell lung cancer: Surgery and SBRT for Stage I NSCLC. Cancer 2015;121:2341-9.

91. Chang JY, Senan S, Paul MA, et al. Stereotactic ablative radiotherapy versus lobectomy for operable stage I nonsmall-cell lung cancer: a pooled analysis of two randomised trials. Lancet Oncol 2015;16:630-7.

92. Guckenberger M. SBRT versus lobectomy in stage I NSCLC: knowns, unknowns and its interpretation. J Thorac Dis 2016;8:2305-9.

93. Anon. A Randomized Phase III Study of Sublobar Resection (SR) versus Stereotactic Ablative Radiotherapy (SAbR) in High Risk Patients with Stage I Non-Small Cell Lung Cancer (NSCLC). Available online: https://www. joltca.org/about

94. Snee MP, McParland L, Collinson F, et al. The SABRTooth feasibility trial protocol: a study to determine the feasibility and acceptability of conducting a phase III randomised controlled trial comparing stereotactic ablative radiotherapy (SABR) with surgery in patients with peripheral stage I non-small cell lung cancer (NSCLC) considered to be at higher risk of complications from surgical resection. Pilot Feasibility Stud 2016;2:5.

95. Anon. Veterans Affairs Lung Cancer Or Stereotactic Radiotherapy (VALOR). Available online: https:// clinicaltrials.gov/ct2/show/NCT02984761

96. Bush DA, Slater JD, Shin BB, et al. Hypofractionated 
proton beam radiotherapy for stage I lung cancer. Chest 2004;126:1198-203.

97. Chang JY, Komaki R, Wen HY, et al. Toxicity and Patterns of Failure of Adaptive/Ablative Proton Therapy for EarlyStage, Medically Inoperable Non-Small Cell Lung Cancer. Int J Radiat Oncol Biol Phys 2011;80:1350-7.

98. Nihei K, Ogino T, Ishikura S, et al. High-dose proton beam therapy for Stage I non-small-cell lung cancer. Int J Radiat Oncol Biol Phys 2006;65:107-11.

99. Chang JY, Zhang X, Wang X, et al. Significant reduction of normal tissue dose by proton radiotherapy compared with three-dimensional conformal or intensity-modulated radiation therapy in Stage I or Stage III non-small-cell lung cancer. Int J Radiat Oncol Biol Phys 2006;65:1087-96.

100.Zhang X, Li Y, Pan X, et al. Intensity-Modulated Proton Therapy Reduces the Dose to Normal Tissue Compared With Intensity-Modulated Radiation Therapy or Passive Scattering Proton Therapy and Enables Individualized Radical Radiotherapy for Extensive Stage IIIB Non-SmallCell Lung Cancer: A Virtual Clinical Study. Int J Radiat Oncol Biol Phys 2010;77:357-66.

101. Register SP, Zhang X, Mohan R, et al. Proton Stereotactic Body Radiation Therapy for Clinically Challenging Cases of Centrally and Superiorly Located Stage I NonSmall-Cell Lung Cancer. Int J Radiat Oncol Biol Phys 2011;80:1015-22.

102. Westover KD, Seco J, Adams JA, et al. Proton SBRT for medically inoperable stage I NSCLC. J Thorac Oncol 2012;7:1021-5.

103. Ohno T. Particle radiotherapy with carbon ion beams. EPMA J 2013;4:9.

104.Ebara T, Shimada H, Kawamura H, et al. Dosimetric Analysis Between Carbon Ion Radiotherapy and Stereotactic Body Radiotherapy in Stage I Lung Cancer. Anticancer Res 2014;34:5099-104.

105. Yamamoto N, Miyamoto T, Nakajima M, et al. A Dose Escalation Clinical Trial of Single-Fraction Carbon Ion Radiotherapy for Peripheral Stage I Non-Small Cell Lung Cancer. J Thorac Oncol 2017;12:673-80.

106. Iwata H, Demizu Y, Fujii O, et al. Long-Term Outcome of Proton Therapy and Carbon-Ion Therapy for Large (T2a-T2bN0M0) Non-Small-Cell Lung Cancer. J Thorac Oncol 2013;8:726-35.

107.Bekelman JE, Hahn SM. Reference Pricing With Evidence Development: A Way Forward for Proton Therapy. J Clin Oncol 2014;32:1540-2.

108. Sheehan M, Timlin C, Peach K, et al. Position statement on ethics, equipoise and research on charged particle radiation therapy. J Med Ethics 2014;40:572-5.

109. Mitin T, Zietman AL. Promise and Pitfalls of HeavyParticle Therapy. J Clin Oncol 2014;32:2855-63.

110. Woody NM, Stephans KL, Andrews M, et al. A Histologic Basis for the Efficacy of SBRT to the lung. J Thorac Oncol 2017;12:510-9.

111. Nikolaev A, Benda RK, Shang CY, et al. Significance of Tumor Cell Histology for Local Control of Early-Stage Non-Small Cell Lung Cancer Treated with Stereotactic Body Radiation Therapy: A Stratified Retrospective Analysis. Int J Radiat Oncol Biol Phys 2016;96:E424.

112.Leeman JE, Rimner A, Montecalvo J, et al. Histologic Subtype of Early-Stage Lung Adenocarcinoma Predicts Failure Patterns in Patients Treated with Stereotactic Body Radiation Therapy. Int J Radiat Oncol Biol Phys 2016;96:S11.

113. Ding L, Getz G, Wheeler DA, et al. Somatic mutations affect key pathways in lung adenocarcinoma. Nature 2008;455:1069-75.

114. Maemondo M, Inoue A, Kobayashi K, et al. Gefitinib or Chemotherapy for Non-Small-Cell Lung Cancer with Mutated EGFR. N Engl J Med 2010;362:2380-8.

115. Mitsudomi T, Morita S, Yatabe Y, et al. Gefitinib versus cisplatin plus docetaxel in patients with non-small-cell lung cancer harbouring mutations of the epidermal growth factor receptor (WJTOG3405): an open label, randomised phase 3 trial. Lancet Oncol 2010;11:121-8.

116. Mok TS, Wu YL, Thongprasert S, et al. Gefitinib or Carboplatin-Paclitaxel in Pulmonary Adenocarcinoma. N Engl J Med 2009;361:947-57.

117. Mak RH, Hermann G, Lewis JH, et al. Outcomes by Tumor Histology and KRAS Mutation Status After Lung Stereotactic Body Radiation Therapy for EarlyStage Non-Small-Cell Lung Cancer. Clin Lung Cancer 2015;16:24-32.

118.Jeong Y, Hoang NT, Lovejoy A, et al. Role of KEAP1/ NRF2 and TP53 Mutations in Lung Squamous Cell Carcinoma Development and Radiation Resistance. Cancer Discov 2017;7:86-101.

Cite this article as: Sebastian NT, Xu-Welliver M, Williams TM. Stereotactic body radiation therapy (SBRT) for early stage non-small cell lung cancer (NSCLC): contemporary insights and advances. J Thorac Dis 2018;10(Suppl 21):S2451-S2464. doi $10.21037 /$ jtd.2018.04.52 